\title{
Fas Receptor Agonist APO010
}

National Cancer Institute

\section{Source}

National Cancer Institute. Fas Receptor Agonist AP0010. NCI Thesaurus. Code C67041.

A recombinant, soluble, hexameric fusion protein consisting of three human Fas ligand (FasL) extracellular domains fused to the dimer-forming collagen domain of human adiponectin with potential pro-apoptotic and antineoplastic activities. Assembled into a soluble hexameric structure mimicking the lig and clustering of endogenous active FasL, Fas receptor agonist APO010 activates the Fas receptor, resulting in caspase-dependent apoptosis in susceptible tumor cell populations. FasL is a transmembrane protein of the tumor necrosis factor (TNF) superfamily and a pro-apoptotic ligand for the death receptor Fas. 